See Article page $\mathrm{XXX}$.

\section{Commentary: Splitting hairs on the crème de la crème of all-arterial revascularization strategies}

\author{
Catherine Wagner, MD, and
}

Robert B. Hawkins, MD, MSc

Shimahara and colleagues ${ }^{1}$ compare long-term outcomes and survival data of patients undergoing bilateral internal thoracic artery (BITA) grafting with the radial artery (RA) as an I graft (BITA-I group) with patients undergoing single internal thoracic artery (SITA) grafting with the RA as the Y graft (SITA-Y group). In this single-center retrospective review spanning from 2002 to 2016, the authors identified 617 BITA-I patients and 516 SITA-Y patients who underwent off-pump aortic no-touch revascualrization. Due to baseline differences, they propensity-score matched 348 pairs. The main finding was superior 10-year survival in the BITA-I group $(79.3 \%$ vs $70.2 \% ; P=.015)$, with the most significant survival benefit derived in patients who were younger than age 77 years and had minimal comorbidities.

Although overall survival was superior in the BITA-I compared with SITA-Y group, the incidence of cardiac death, graft patency, and rate of re-revascularization were all similar between the 2 groups. The authors argue that a higher rate of unknown and "nonmalignancy" causes of death in the SITA-Y group may in fact be unrecognized cardiac disease contributing to death and related to their revascularization strategy. ${ }^{1}$ Possible etiologies for similar rates of graft patency and re-revascularization between the

\footnotetext{
From the Department of Cardiac Surgery, University of Michigan, Ann Arbor, Mich. Disclosures: The authors reported no conflicts of interest.

The Journal policy requires editors and reviewers to disclose conflicts of interest and to decline handling or reviewing manuscripts for which they may have a conflict of interest. The editors and reviewers of this article have no conflicts of interest.

Received for publication Dec 18, 2021; revisions received Dec 18, 2021; accepted for publication Dec 20, 2021.

Address for reprints: Robert B. Hawkins, MD, MSc, Department of Cardiac Surgery, University of Michigan, 5353 Frankel Cardiovascular Center, Ann Arbor, MI 48109 (E-mail: Robertbh@med.umich.edu).

J Thorac Cardiovasc Surg 2021; $\mathbf{\square}: 1-2$

0022-5223/\$0.00

Published by Elsevier Inc. on behalf of The American Association for Thoracic Surgery

https://doi.org/10.1016/j.jtcvs.2021.12.032
}

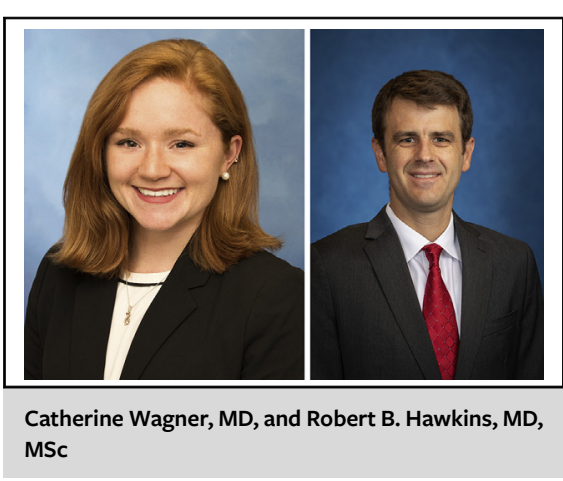

\author{
CENTRAL MESSAGE \\ Patient selection and surgeon \\ experience are critical to realizing \\ any potential survival benefit of \\ BITA over SITA for all-arterial \\ revascularization with an addi- \\ tional radial artery.
}

SITA and BITA groups were not explored; however, this would be important to investigate because these are critical outcomes measures in coronary artery bypass grafting (CABG). These findings require some conjecture to identify differences between the groups, but the 10-year survival rates of $79 \%$ and $70 \%$ are excellent, and the minimal statistical differences may be due to the low event rates suggesting low clinical significance.

The authors describe that patients younger than age 77 years, with no comorbidities (ie, no history of diabetes, cerebrovascular events, peripheral vascular disease, left ventricular dilation, or low ejection fraction) and with triple-vessel disease had the most significant improvement in survival benefit from BITA-I compared with SITA-Y. ${ }^{1}$ This highlights the importance of patient selection and surgeon experience when choosing a revascularization strategy. In Japan, CABG methods and patient characteristics are substantially different than in the United States. In Japan, $65 \%$ of CABG cases are off-pump, whereas $<15 \%$ are off-pump in the United States. ${ }^{2}$ In the United States, $10.6 \%$ of patients undergo multiarterial grafting compared with this work, where all-arterial aortic notouch off-pump revascularization is the standard revascualrization strategy. ${ }^{3}$ Then consider that in the United States nearly $50 \%$ of CABG patients have diabetes. ${ }^{4}$ This helps explain why a recent Society of Thoracic Surgeons analysis 
found that SITA with RA was associated with lower operative mortality and deep sternal wound infections compared with BITA.

The authors should be congratulated on an excellent study comparing 2 advanced all-arterial revascularization strategies. They have identified characteristics (age younger than 77 years, no comorbities, and 3-vessel disease) of patients who may benefit from BITA with RA as opposed to SITA with RA. Understanding the nuances of the offpump technique and highly selected patient characteristics for those matched in the cohort are important for surgeons to realize and dramatically limit the generalizability of this study in Europe and North America. As we push for greater adoption of multiarterial grafting, we should do so in a safe manner with individualized strategies that balance patient risk factors with the optimal graft combination.

\section{References}

1. Shimahara Y, Fukushima S, Kawamoto N, Tadokoro N, Nakai M, Kobayashi J, et al. Additional survival benefit of bilateral in situ internal thoracic artery grafting with composite radial artery graft in total arterial off-pump coronary artery bypass grafting. J Thorac Cardiovasc Surg. 2022. XXX:XXX.

2. Kuwahara G, Tashiro T. Current status of off-pump coronary artery bypass. Ann Thorac Cardiovasc Surg. 2020;26:125-32.

3. Schwann TA, Habib RH, Wallace A, Shahian D, Gaudino M, Kurlansky P, et al. Bilateral internal thoracic artery versus radial artery multi-arterial bypass grafting: a report from the STS database. Eur J Cardiothorac Surg. 2019;56: 926-34.

4. D'Agostino RS, Jacobs JP, Badhwar V, Fernandez FG, Paone G, Wormuth DW, et al. The Society of Thoracic Surgeons Adult Cardiac Surgery database: 2018 update on outcomes and quality. Ann Thorac Surg. 2018;105:15-23. 